\title{
TERMITICIDAL ACTIVITY OF METHANOL EXTRACT OF PEGAGAN (Centella asiatica L. Urban) TOWARD Coptotermes curvignathus Holmgren
}

\section{Dina Erliana, Charles Banon, Avidlyandi Avidlyandi, Rahmaga Febriansyah, Morina Adfa*}

Jurusan Kimia, Fakultas Matematika dan Ilmu Pengetahuan Alam, Universitas Bengkulu. Jalan W.R. Supratman, Kandang Limun, Kota Bengkulu, Bengkulu, Indonesia *morina@unib.ac.id

Doi: https://doi.org/10.31943/mangiferaedu.v6i2.125

Received: April 07, $2021 \quad$ Accepted: January 19, 2022 Published: January 31, 2022 Citation: Erliana, D., Banon, C., Avidlyandi, A., Febriansyah, R., \& Adfa, M. (2022). Termiticidal Activity of Methanol Extract of Pegagan (Centella asiatica L. Urban) toward Coptotermes curvignathus Holmgren. Jurnal Mangifera Edu, $6(2), 129-138$

\section{ABSTRACT}

Termiticide activity of methanol extract of Centella asiatica L. Urban against Coptotermes curvignathus Holmgren was investigated using the no-choice test. The chemical components of methanol extract of C. asiatica were identified by GC-MS. The antitermite activity showed that the percentage of termite mortality increased when the concentrations of extract increased. The concentrations of $25 \%$ indicated the highest termite mortality which reached $100 \%$ on the sixth day. Profiling GC-MS methanol extract of $C$. asiatica revealed 85 chemical components. Based on MS spectral data, 56 chemical components were identified which were grouped into fatty acids (27.09\%), esters $(23.73 \%)$, hydrocarbons (16.56\%), ethers (8.28\%), sesquiterpenes (1.61\%), alcohol $(1.55 \%)$, aldehydes $(3.50 \%)$, monoterpenes $(1.08 \%)$, diterpenes $(0.67 \%)$, steroids $(0.43 \%)$, and ketones $(0.31 \%)$. Among these, the presence of palmitic acid, patchouli alcohol, and $\beta$ caryophyllene may be responsible for its termiticide activity. Other compounds such as triterpenoids, saponins, flavonoids, tannins, steroids, and glycosides that were reported previously not detected by GC-MS in this study, possibly contributing to its activity.

Keywords: Centella asiatica, Coptotermes curvignathus, Termites, GC-MS

\section{ABSTRAK}

Aktivitas antirayap ekstrak metanol egagan (Centella asiatica L. Urban) terhadap rayap Coptotermes curvighnatus Holmgren telah diteliti dengan menggunakan metode no choice test, dan penentuan komponen kimia volatile menggunakan GC-MS. Hasil uji aktivitas antirayap diperoleh persentase kematian rayap meningkat seiring dengan bertambahnya konsentrasi ekstrak pegagan yang diaplikasikan. Pada konsentrasi $25 \%$ menyebabkan kematian rayap tertinggi yang mencapai $100 \%$ pada hari ke-6. Profil GCMS memperlihatkan 85 komponen kimia penyusun ekstrak metanol C. asiatica. Dari data spektrum MS teridentifikasi 56 komponen kimia, yang dikelompokkan kedalam asam-asam lemak (27,09\%), ester (23,73\%), hidrokarbon $(16,56 \%)$, eter $(8,28 \%)$, sesquiterpen (1,61\%), alkohol (1,55\%), aldehid (3,50\%), monoterpen (1,08\%), diterpen $(0,67 \%)$, steroid $(0,43 \%)$, dan keton $(0,31 \%)$. Diantara senyawa-senyawa tersebut, diduga keberadaan palmitic acid, patchouli alcohol, $\beta$-caryophyllene mungkin bertanggung 
Jurnal Mangifera Edu, Volume 6, Issue 2, January 2022, 129-138

jawab terhadap aktivitas antirayap. Kehadiran senyawa lain seperti triterpenoid, saponin, flavonoid, tannin, steroid, dan glikosida yang sudah dilaporkan dari tanaman C. asiatica yang tidak terdeteksi oleh GC-MS kemungkinan ikut berkontribusi terhadap aktivitasnya.

Kata Kunci: Centella asiatica, Coptotermes curvignathus, Termites, GC-MS

\section{PENDAHULUAN}

Pegagan (Centella asiatica L. Urban) adalah tanaman merambat yang berkembang secara luas di tempat teduh, berawa, lembab dan basah seperti persawahan. Berdasarkan hasil uji fitokimia, C. asiatica mengandung senyawa-senyawa metabolit sekunder seperti alkaloid, glikosida, terpenoid, steroid, flavonoid, tanin dan saponin (Arumugam et al., 2011).

C. asiatica dilaporkan memiliki berbagai aktivitas farmakologis seperti aktivitas antimikroba (Sieberi et al., 2020), antikanker (Aizad et al., 2021), penyembuhan luka, imunomodulator, anti-peradangan, hepatoprotektif, insektisida, dan antioksidan (Roy et al., 2013). Berdasarkan berbagai aktivitas farmakologis yang ditunjukkannya, aktivitas insektisida $C$. asiatica menjadi hal menarik untuk diteliti karena sangat terbatas sekali informasi yang tersedia. Beberapa penelitian sebelumnya melaporkan aktivitas insektisida daun pegagan terhadap Anopheles subpictus dengan nilai LC s0 $_{50}$ sebesar 26,62 ppm (Bagavan et al., 2009). Ekstrak etanol tanaman pegagan juga memiliki aktivitas antifeedant terhadap larva Spodoptera litura dengan konsentrasi efektif minimum 625 ppm (Malini et al., 2016).

Dari penelusuran literatur belum pernah diteliti penggunaan tanaman pegagan sebagai antirayap. Rayap merupakan serangga yang mempunyai peranan penting sebagai dekomposer primer dengan cara menghancurkan kayu atau bahan organik lainnya dan mengembalikan sebagai hara ke dalam tanah. Namun rayap menjadi hama ketika mereka mulai merusak konstruksi bangunan berbahan dasar kayu dan merusak tanaman perkebunan sehingga mengakibatkan kerugian ekonomi yang signifikan (Nandika et al., 2003).

Salah satu jenis rayap yang paling banyak menyebabkan kerusakan di Indonesia adalah Coptotermes curvignathus Holmgren. Hal ini dikarenakan C. curvignathus mampu menyerang komponen bangunan yang berada di atas permukaan tanah dengan melewati liang liang kembara dan mampu menerobos pondasi bangunan (Savitri et al., 2016).

Pada umumnya hama rayap dikendalikan dengan menggunakan termitisida sintetik. Beberapa termitisida sintetik dilaporkan mempunyai efek negatif terhadap lingkungan dan kesehatan. Pemakaian termitisida yang sama secara terus menerus juga menyebabkan terjadinya resistensi hama. Oleh karena itu diperlukan adanya termitisida alami atau termitisida organik yang ramah lingkungan sebagai pengganti termitisida sintetik. 
Jurnal Mangifera Edu, Volume 6, Issue 2, January 2022, 129-138

Berdasarkan uraian diatas, salah satu tanaman yang berpotensi dikembangkan sebagai termitisida alami adalah tanaman pegagan ( $C$. asiatica). Sejauh ini belum ada laporan tentang penggunaan ekstrak tanaman pegagan terkait aktivitas antirayap. Oleh karena itu penelitian ini dilakukan untuk mengetahui aktivitas antirayap ekstrak metanol tanaman $C$. asiatica terhadap rayap $C$. curvignathus dan penentuan komponen kimianya menggunakan GC-MS

\section{METODOLOGI PENELITIAN}

\section{Bahan Penelitian}

Sampel yang digunakan pada penelitian ini adalah seluruh bagian tumbuhan pegagan (C. asiatica). Tanaman C. asiatica diperoleh dari wilayah Desa Talang Sebaris Kecamatan Air Periukan, Kabupaten Seluma, Provinsi Bengkulu. Rayap uji adalah Coptotermes curvignathus Holmgren. Bahan lainnya adalah: metanol teknis, kertas saring Whatman No.1 berdiameter $9 \mathrm{~cm}$ sebagai umpan rayap, dan akuades.

\section{Alat dan Instrumen Penelitian}

Peralatan yang digunakan adalah: rotary evaporator (Heidolph), oven, neraca analitik (aeADAM), cawan petri diameter dalam 90 x $20 \mathrm{~mm}$ (Normax), desikator, pipet mikro, dan peralatan gelas umumnya, serta GCMS-QP2010S SHIMADZU.

\section{Proses Ekstraksi}

Sampel segar seluruh bagian tumbuhan $C$. asiatica dibersihkan, setelah dibersihkan dipotong kecil-kecil dan ditabur diatas kertas koran kemudian diletakkan didalam ruangan yang tidak terkena cahaya matahari langsung (kering angina) selama 1 minggu. Sebanyak $710 \mathrm{~g}$ tumbuhan $C$. asiatica kering, dimasukkan kedalam 3 buah botol gelap kemudian dimaserasi menggunakan pelarut metanol (5,4 L) dalam kurun waktu 4 hari. Hasil maserasi disaring dan maserat diuapkan pelarutnya menggunakan rotary evaporator pada suhu 45 $50^{\circ} \mathrm{C}$ agar didapatkan ekstrak pekat metanol. Selanjutnya residu tanaman pegagan diremaserasi, proses remaserasi dilakukan dengan menambahkan pelarut secara berulang sampai proses ekstraksi sempurna yang ditandai dengan maserat yang diperoleh menjadi tak berwarna.

\section{Penentuan Komponen Kimia Ekstrak Metanol Centella asiatica}

Ekstrak metanol yang diperoleh kemudian ditentukan komponen kimia penyusunnya menggunakan GCMS-QP2010S SHIMADZU di Laboratorium Kimia Organik UGMYogyakarta. Kondisi alat sebagai berikut: kolom Rtx 5 MS, panjang $30 \mathrm{~m}$, ID 0,25 mm, gas pembawa Helium dan pengion EI 70 Ev. Kromatogram GC dan spektrum massa yang 
Jurnal Mangifera Edu, Volume 6, Issue 2, January 2022, 129-138

didapat dibandingkan dengan senyawa-senyawa standar yang ada pada Bank data National Institute Standar of Technology (NIST)-62 (62 enteries), Willey 229 library dan pesticd.

\section{Uji Aktivitas Termitisida Ekstrak Metanol Centella asiatica}

Rayap uji dikoleksi dari kayu yang terserang jenis rayap C. curvignathus pada area kampus utama Universitas Bengkulu. Rayap yang diperoleh dibawa ke laboratorium kimia organic agar rayap dapat beradaptasi di lingkungan laboratorium. Rayap tersebut dimasukkan kedalam toples yang sudah diberi sisa-sisa potongan kayu dan tanah dari tempat rayap diambil. Rayap yang digunakan untuk pengujian sebanyak 20 ekor rayap pekerja dan 2 ekor rayap prajurit yang aktif.

Metode yang digunakan untuk uji aktivitas termitisida adalah metode umpan paksa/no choice test. Ekstrak metanol $C$. asiatica dibuat dalam 6 tingkatan konsentrasi dengan rasio persen massa ekstrak (g) terhadap massa kertas saring umpan (g) dikali 100\%. Konsentrasi uji yang digunakan adalah 0\% (pelarut saja sebagi kontrol negatif), 5, 10, 15, 20 dan $25 \%$ b/b). Masing-masing pengujian dilakukan pengulangan sebanyak 4 kali. Ekstrak dilarutkan dengan menggunakan campuran pelarut metanol dan etil asetat dengan perbandingan 0,8 dan 0,2 mL. Selanjutnya larutan tersebut diteteskan pada kertas saring umpan secara merata. Kertas saring yang telah ditetesi ekstrak uji dan kontrol didiamkan selama 48 jam sampai semua pelarut menguap. Kemudian kertas saring tersebut ditimbang kembali untuk menentukan massa kertas saring yang sudah bebas pelarut. Kertas saring umpan yang telah diuapkan pelarutnya dimasukkan kedalam cawan petri, lalu dimasukkan 20 ekor rayap pekerja aktif dan 2 ekor rayap prajurit aktif. Setelah itu cawan petri ditutup dan disimpan di tempat yang gelap pada suhu ruangan selama 14 hari. Setiap hari air dan kelembapan pada cawan petri dikontrol dan angka kematian rayap diamati setiap harinya selama 14 hari dan dihitung jumlah akumulatifnya pada hari terakhir. Persentase kematian rayap dihitung dengan menggunakan rumus sebagai berikut:

$\%$ Kematian Rayap $=\frac{\text { Jumlah Rayap Mati }}{\text { Jumlah Rayap Uji }} \times 100 \%$ (Adfa et al., 2010)

\section{HASIL DAN PEMBAHASAN}

\section{Ekstraksi dan Penentuan Komponen Kimia}

Tanaman pegagan (C. asiatica) kering angin sebanyak $710 \mathrm{~g}$ dimaserasi menggunakan pelarut metanol sebanyak 5,4 L selama 4 hari, dan proses remaserasi sebanyak 6 kali. Setelah pelarut diuapkan dengan rotary evaporator didapatkan ekstrak pekat $C$. 
Jurnal Mangifera Edu, Volume 6, Issue 2, January 2022, 129-138

asiatica berwarna hijau. Massa ekstrak metanol pekat yang diperoleh adalah 113,17g dengan rendemen $15,9 \%$.

Analisis komponen kimia ekstrak metanol C. asiatica menggunakan GC-MS didapat 85 puncak yang menunjukkan jumlah senyawa kimia yang mudah menguap terkandung didalam ekstrak tersebut (Tabel 1). Seperti beberapa laporan sebelumnya, bahwa teknik GCMS akan bekerja dengan baik untuk menganalisis senyawa-senyawa yang bersifat volatile. Berdasarkan data TIC kromatogran GC-MS yang dibandingkan dengan spektrum MS pembanding dari NIST, Willey 229 Library dan Pesticd Library maka teridentifikasi 56 komponen kimia penyusun ekstrak metanol C. asiatica, sedangkan 29 komponen lainnya belum dapat diidentifikasi karena rendahnya nilai indeks similarity.

Berdasarkan analisis data GC-MS, ekstrak metanol tanaman pegagan memiliki empat komponen utama dengan konsentrasi area terbesar terdapat pada puncak nomor 50 , 80, 37 dan 47 dengan konsentrasi area berturut-turut: 25,54\%; 9,03\%; 7,01\%; dan 6,99\%. Keempat komponen kimia tersebut teridentifikasi sebagai: palmitic acid, di-n-octyl phthalate, 1,2-Epoxyhexadecane, dan methyl palmitate. Seperti yang tertera pada Tabel 1, selain keempat komponen utama diatas, terdapat 52 senyawa minor lainnya yang teridentifikasi.

Komponen-komponen kimia yang teridentifikasi GC-MS dari ekstrak metanol $C$. asiatica dapat dikelompokkan kedalam golongan asam-asam lemak (27,09\%), golongan ester $(23,73 \%)$, golongan hidrokarbon $(16,56 \%)$, golongan eter $(8,28 \%)$, golongan sesquiterpen $(1,61 \%)$, golongan alkohol $(1,55 \%)$, golongan aldehid $(3,50 \%)$, golongan monoterpen $(1,08 \%)$, golongan diterpen $(0,67 \%)$, golongan steroid $(0,43 \%)$, dan golongan keton $(0,31 \%)$. Hal ini didukung oleh penelitian sebelumnya, Ghosh \& Indra (2014) melaporkan profil GC-MS ekstrak etanol C. asiatica yang mengandung asam-asam lemak dan senyawa lainnya seperti methyl pyromeconic acid (maltol) (2,24\%), cyclohexanecarboxylic acid (28,02\%), 5-methoxy-2,2,8,8-tetramethyl-acetate (1,01\%), methoxy vinyl phenol (3,06\%), beta-D-ribofuranoside (12,59\%), Nobileti (0,87\%). Sedangkan Paudel et al., (2017) melaporkan bahwa C. asiatica mengandung minyak atsiri yang didominasi oleh golongan sesquiterpen yaitu: (E) - $\beta$-farnesene $(26,5 \%), \alpha$-humulena (20,9\%), dan (E) $\beta$-caryophyllene (13,3\%).

\section{Aktivitas Termitisida Ekstrak Metanol Centella asiatica}

Hasil uji aktivitas membunuh rayap/termitisida ekstrak metanol C. asiatica terhadap rayap Coptotermes curvignathus menujukkan bahwa ekstrak mempunyai aktivitas antirayap pada berbagai konsentrasi uji (\%b/b) menggunakan metode umpan paksa (Gambar 1). Pada 
Gambar 1, dapat dilihat bahwa persentase kematian rayap berbanding lurus terhadap besarnya konsentrasi ekstrak yang diberikan pada kertas saring umpan. Persentase kematian rayap setiap harinya semakin meningkat seiring dengan meningkatnya konsentrasi dari ekstrak metanol $C$. asiatica yang diberikan. Kematian rayap tertinggi diberikan pada konsentrasi uji tertinggi (25\%), rayap mengalami kematian 100\% pada hari ke 6 dan konsentrasi ekstrak 20\%, rayap mengalami kematian 100\% pada hari ke 11. Sedangkan konsentrasi ekstrak 5\%, 10\%, dan 15\% rayap mengalami kematian berturut-turut 71,59\%; 92,05\%; dan 96,59\% pada hari ke 14. Dapat dilihat bahwa kematian rayap mengalami peningkatan yang signifikan pada hari ke 5 pada semua konsentrai uji, mulai dari konsentrasi terendah yaitu 5\% hingga konsentrasi tertinggi 25\% dengan persentase kematian rayap berturut-turut yaitu 43,18\%; 51,14\%; 69,32\%; 81,82\%; dan 93,18\%. Pada konsentrasi 0\% (kontrol), persentase kematian rayap hingga hari ke 14 yaitu sebesar 13,64\%.

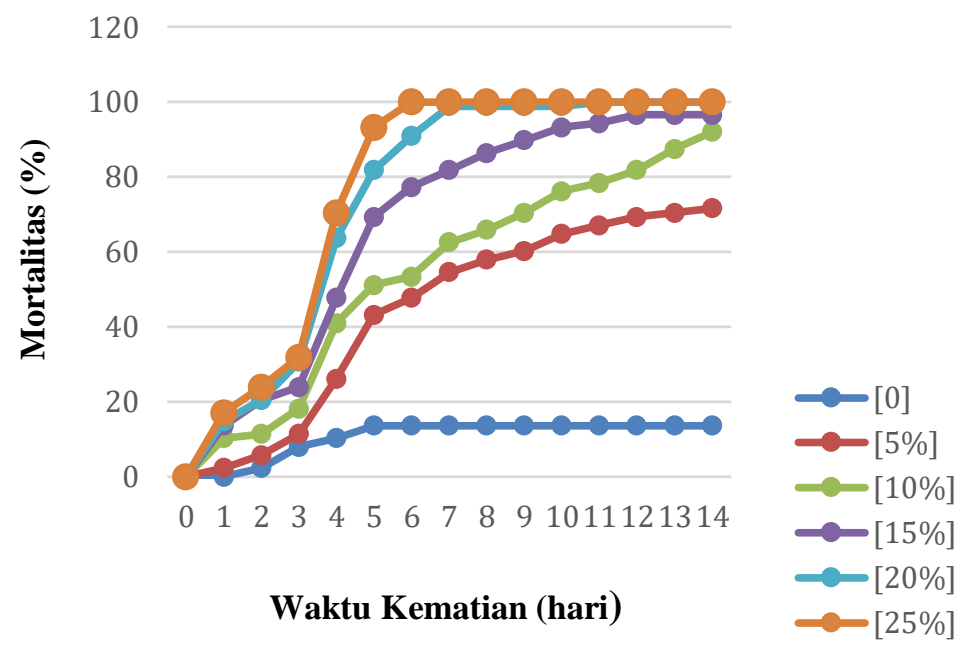

\section{Gambar 1. Aktivitas termitisida ekstrak metanol pegagan (Centella asiatica L. Urban) terhadap Coptotermes curvignathus}

Kematian rayap kemungkinan disebabkan oleh adanya senyawa-senyawa kimia yang dikandung ekstrak metanol C. asiatica. Hasil GC-MS menunjukkan bahwa ekstrak metanol tanaman pegagan banyak mengandung asam-asam lemak diantaranya palmitic acid dengan persentase terbesar. Menurut Rocha et al. (2020) asam palmitat memiliki bioaktivitas sebagai anti-protozoa dan anti-bakteri, diduga dengan kehadiran asam palmitat tersebut dapat membunuh protozoa yang terdapat dalam perut rayap melalui gangguan terhadap aktivitas enzim.

Tabel 1. Kandungan Kimia Ekstrak Metanol Centella asiatica yang Dideteksi dengan GC-MS 
Jurnal Mangifera Edu, Volume 6, Issue 2, January 2022, 129-138

\begin{tabular}{|c|c|c|c|c|c|c|c|}
\hline $\begin{array}{c}\text { No } \\
\text { Puncak }\end{array}$ & Komponen & $\begin{array}{c}\text { RT } \\
\text { (menit) }\end{array}$ & $\begin{array}{l}(\%) \\
\text { Area }\end{array}$ & $\begin{array}{c}\text { No } \\
\text { Puncak }\end{array}$ & Komponen & $\underset{\text { (menit) }}{\text { RT }}$ & $\begin{array}{l}(\%) \\
\text { Area }\end{array}$ \\
\hline 1 & Tetradecane & 10,180 & 0,37 & 44 & Tidak Teridentifikasi & 33,387 & 0,61 \\
\hline 2 & Dodecane & 10,283 & 0,64 & 45 & Glycidylhexadecylether & 33,550 & 0,53 \\
\hline 3 & 4-Methyl Undecane & 10,367 & 0,68 & 46 & Lignoceryl alcohol & 33,697 & 1,03 \\
\hline 4 & 3,3-Dimethyloctane & 10,467 & 0,91 & 47 & Methyl palmitate & 33,808 & 6,99 \\
\hline 5 & 2,4-Dimethylhexane & 17,076 & 0,23 & 48 & $\begin{array}{l}2,6,10,14-\text { Tetramethyl } \\
\text { pentadecane }\end{array}$ & 34,288 & 0,33 \\
\hline 6 & Hexadecane & 17,442 & 1,32 & 49 & 3-Ethyl-3-methylheptane & 34,432 & 0,18 \\
\hline 7 & Tidak Teridentifikasi & 17,700 & 0,23 & 50 & Palmitic acid & 34,768 & 25,54 \\
\hline 8 & Tidak Teridentifikasi & 17,875 & 0,16 & 51 & Oleic acid & 35,189 & 0,14 \\
\hline 9 & Tridecane & 18,849 & 0,49 & 52 & Tidak Teridentifikasi & 35,292 & 0,61 \\
\hline 10 & Tidak Teridentifikasi & 19,403 & 0,14 & 53 & $\begin{array}{l}\text { 3-(isopropyl)-6- } \\
\text { methylcyclohex-2-en-1-ol }\end{array}$ & 35,392 & 0,20 \\
\hline 11 & $\beta$-Caryophyllen & 21.872 & 0,60 & 54 & 1-Octadecyne & 35,510 & 0,17 \\
\hline 12 & 1-chlorotetradecane & 22.628 & 0,24 & 55 & Pentadecanoic Acid & 35,841 & 0,52 \\
\hline 13 & Tidak Teridentifikasi & 22,769 & 0,29 & 56 & 1,2-Epoxyhexadecane & 36,833 & 0,24 \\
\hline 14 & Tidak Teridentifikasi & 22,872 & 0,41 & 57 & 1-Phenyl-1-nonyne & 36,978 & 3,59 \\
\hline 15 & $\begin{array}{l}\text { 2-(7-Heptadecynyloxy)t } \\
\text { etrahydro- } 2 \mathrm{H} \text { - pyran }\end{array}$ & 22,996 & 0,13 & 58 & 9,12-Hexadecanoid acid & 37,196 & 3,57 \\
\hline 16 & Tidak Teridentifikasi & 23,358 & 0,27 & 59 & Linoleoyl chloride & 37,315 & 2,86 \\
\hline 17 & Tidak Teridentifikasi & 23,478 & 1,10 & 60 & $\begin{array}{l}\text { Hexadecanal diallyl } \\
\text { acetal }\end{array}$ & 37,438 & 1,14 \\
\hline 18 & Tidak Teridentifikasi & 23,859 & 0,20 & 61 & Octadecane & 37,606 & 0,66 \\
\hline 19 & Pentadecane & 24,661 & 0,65 & 62 & Methyl stearate & 37,810 & 1,20 \\
\hline 20 & Tidak Teridentifikasi & 24,823 & 0,26 & 63 & Trans-2-tridecenal & 38,131 & 3,50 \\
\hline 21 & Dihydroactinidolide & 25,008 & 0,36 & 64 & Tidak Teridentifikasi & 38,300 & 0,44 \\
\hline 22 & Tidak Teridentifikasi & 25,008 & 0,36 & 65 & $\begin{array}{l}2,6,10- \\
\text { Trimethyldodecane }\end{array}$ & 38,407 & 0,49 \\
\hline 23 & Lauric acid & 25,640 & 0,46 & 66 & Stearic acid & 38,576 & 0,87 \\
\hline 24 & Tidak Teridentifikasi & 25,992 & 0,19 & 67 & trans-2-Hexenylbutyrate & 38,642 & 0,49 \\
\hline 25 & $\beta$-Caryophylleneoxide & 26,245 & 0,73 & 68 & $\begin{array}{l}\text { 1,e-11,z-13- } \\
\text { Octadecatriene }\end{array}$ & 38,835 & 0,74 \\
\hline 26 & Citronellyl acetat & 26,951 & 0,16 & 69 & Tidak Teridentifikasi & 39,163 & 0,19 \\
\hline 27 & Patchouli alcohol & 28,566 & 0,28 & 70 & $\begin{array}{l}\text { 2,2- dimethyl-1-acetil- } \\
\text { cyclohexane }\end{array}$ & 39,576 & 0,31 \\
\hline 28 & Nonadecane & 28,723 & 0,81 & 71 & Tidak Teridentifikasi & 40,110 & 0,28 \\
\hline 29 & Tidak Teridentifikasi & 28,833 & 0,34 & 72 & Tidak Teridentifikasi & 40,317 & 0,14 \\
\hline 30 & 3-octadecene & 29,417 & 0,58 & 73 & Pentadecane & 40,959 & 0,19 \\
\hline 31 & Tidak Teridentifikasi & 29,533 & 0,17 & 74 & 15-Tetracosenoicacid & 41,463 & 0,67 \\
\hline 32 & Tidak Teridentifikasi & 29,728 & 0,55 & 75 & 1-Hexadecanol & 41,949 & 0,52 \\
\hline 33 & Myristic acid & 30,318 & 0,95 & 76 & Tidak Teridentifikasi & 42,132 & 0,34 \\
\hline 34 & Fenchyl alcohol & 30,675 & 0,16 & 77 & Tidak Teridentifikasi & 42,525 & 0,18 \\
\hline 35 & $\begin{array}{l}(1 S, 2 S, 5 R)-(+)- \\
\text { Neomenthol }\end{array}$ & 31,080 & 0,36 & 78 & Tidak Teridentifikasi & 42,679 & 0,25 \\
\hline 36 & Isopropyl myristate & 31,619 & 1,04 & 79 & Eicosane & 44,357 & 0,41 \\
\hline 37 & 1,2-Epoxyhexadecane & 31,876 & 7,01 & 80 & Di-n-octylphthalate & 44,961 & 9,03 \\
\hline 38 & $\begin{array}{l}\text { 6,10-Dimethylundecan- } \\
\text { 2-one }\end{array}$ & 32,033 & 1,46 & 81 & Tidak Teridentifikasi & 45,954 & 0,23 \\
\hline 39 & Tidak Teridentifikasi & 32,225 & 0,28 & 82 & Hexacosane & 48,984 & 0,21 \\
\hline 40 & Tidak Teridentifikasi & 32,403 & 0,67 & 83 & Tidak Teridentifikasi & 50,423 & 0,22 \\
\hline 41 & Dibutyl phthalate & 32,511 & 0,43 & 84 & $\begin{array}{l}22,23- \\
\text { dihydroergosterol }\end{array}$ & 52,341 & 0,43 \\
\hline 42 & $\begin{array}{l}\text { 3,7,11,15-tetramethyl- } \\
\text { 2- hexadecen-1-ol }\end{array}$ & 32,800 & 2,65 & 85 & Tidak Teridentifikasi & 53,350 & 0,36 \\
\hline 43 & Tidak Teridentifikasi & 33,250 & 0,24 & & & & \\
\hline
\end{tabular}


Selain asam-asam lemak terdapat juga senyawa patchouli alcohol pada puncak nomor 27 yang diduga berperan aktif dalam membunuh rayap. Zhu et al., (2003) menyatakan bahwa senyawa patchouli alcohol aktif dalam membunuh rayap, rayap mengalami kejangkejang dalam beberapa menit, menjadi lumpuh, dan akhirnya mati. Semua rayap mati dalam jangka waktu 72 jam setelah pemberian patchouli alcohol dengan dosis 50mg. Senyawa sesquiterpen seperti $\beta$-caryophyllene $(0.60 \%)$ terlihat pada puncak no 11 , senyawa tersebut juga diduga mempunyai peran pada ekstrak metanol $C$. asiatica untuk membunuh rayap. Sejalan dengan laporan Ashitani et al., (2013) yang menyatakan bahwa senyawa $\beta$ caryophyllene berperan sebagai penghambat makan pada rayap tanah Reticulitermes speratus Kolbe. Struktur dari senyawa-senyawa yang diduga berperan aktif terhadap aktivitas antirayap dapat dilihat pada Gambar 2.

Selain senyawa senyawa volatile yang terdeteksi menggunakan GC-MS, tentunya senyawa-senyawa non volatile yang dikandung ekstrak metanol $C$. asiatica yang tidak terdeteksi menggunakan GC-MS diduga ikut berperan dalam aktivitas termitisidanya. Senyawa-senyawa tersebut seperti triterpenoid, saponin, flavonoid, tannin, steroid, dan glikosida telah berhasil diisolasi dari tanaman C. asiatica (Jamil et al., 2007).

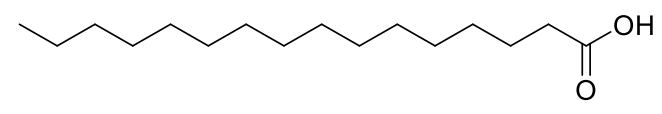

Palmitic Acid

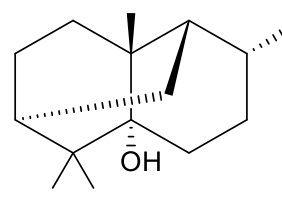

Patchouli Alcohol

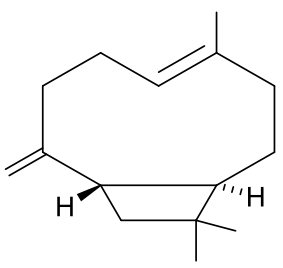

ß-Caryophyllene

Gambar 2. Senyawa-senyawa metabolit sekunder ekstrak metanol pegagan (Centella asiatica L. Urban) yang diduga berperan dalam aktivitas termitisida

\section{SIMPULAN}

Dari hasil penelitian dapat disimpulkan bahwa ekstrak metanol tanaman pegagan (Centella asiatica L. Urban) memiliki aktivitas termitisida terhadap Coptotermes curvignathus Holmgren. Hal ini ditunjukkan dengan semakin tinggi konsentrasi ekstrak metanol pegagan yang ditambahkan pada kertas saring umpan maka semakin tinggi pula mortalitas rayap. Kematian rayap tertinggi pada konsentrasi uji $25 \%$ yang menyebabkan $100 \%$ mortalitas rayap pada hari ke 6 . Aktivitas ini berhubungan dengan kandungan kimia yang dimiliki ekstrak metanol C. asiatica. Senyawa yang diduga aktif adalah palmitic acid, 
Jurnal Mangifera Edu, Volume 6, Issue 2, January 2022, 129-138

patchouli alcohol dan $\beta$-caryophyllene. Untuk penelitian selanjutnya perlu dilakukan pendeteksian kandungan kimia ekstrak metanol $C$. asiatica menggunakan LC-MS sehingga komponen polar dapat terdeteksi dan diharapkan kedepannya potensi pegagan sebagi biopestisida dapat dikembangkan.

\section{DAFTAR PUSTAKA}

Adfa M., Yoshimura, T., Komura, K., \& Koketsu, M. (2010). Antitermite Activities of Coumarin Derivatives and Scopletin from Protium javanicum Burm. f. Journal of Chemical Ecology, 36(1), 720-726.

Aizad, S., Zubairi, S.I., Yahaya, B.H. \& Lazim, A.M. (2021). Centella asiatica Extract Potentiates Anticancer Activity in an Improved 3-D PHBV-Composite-CMC A549 Lung Cancer Microenvironment Scaffold. Arabian Journal for Science and Engineering, 46(6), 5313-5325.

Arumugam, T., Ayyanar, M., Pillai, Y.J.K., \& Sekar, T. (2011). Phytochemical Screening and Antibacterial Activity of Leaf and Callus Extracts of Centella asiatica. Bangladesh Journal of Pharmacology, 6(1), 55-60.

Ashitani, T., Kusumoto, N., Borg-Karlson, A.K., Fujita, K., \& Takahashi, K. (2013). Antitermite Activity of $\beta$-Caryophyllene Epoxide and Episulfide. Zeitschrift für Naturforschung C, 68(7-8), 302-306.

Bagavan A., Kamaraj, C., Elango, G., Abduz Zahir, A., \& Abdul Rahuman, A. (2009). Adulticidal and Larvicidal Efficacy of Some Medicinal Plant Extracts against Tick, Fluke and Mosquitoes. Veterinary Parasitology, 166, 286-292.

Ghosh K., \& Indra, N. (2014). Phytochemistry, In Vitro Free Radical Scavenging, Chelating and Toxicity of Centella asiatica L. (Apiaceae) Ethanolic Leaf Extract. International Journal of Pharmaceutical Sciences Review and Research, 29(1), 328-334.

Jamil, S.S., Nizami, Q., \& Salam, M. (2007). Centella asiatica (Linn.) Urban a Review. Natural Product Radiance, 6(2), 158-170.

Malini D.M., Madihah, Melanie, Kasmara, H., Maharani, R., Novianti, V., Rozi, F., \& Hermawan, W. (2016). Antifeedant Activity of Ethanol Extracts of Five Selected Plants against Larvae of Taro Carterpillar (Spodoptera litura Fabricius, 1775). Proceeding International Symposium for Sustainable Humonsphere, 37-47.

Nandika D., Rismayadi, Y., \& Diba, F. (2003). Rayap: Biologi dan Pengendaliannya. Surakarta: Muhammadiyah Univ. Press.

Paudel, P., Satyal, P., Dosoky, N.S., \& Setzer, W.N. (2017). Chemical Composition and Biological Activity of Centella asiatica Essential Oil from Nepal. American Journal of Essential Oils and Natural Products, 5(4), 05-08. 
Jurnal Mangifera Edu, Volume 6, Issue 2, January 2022, 129-138

Rocha, E.D.O., Chang, R., do Nascimento, E.A., Martins, M.M., de Morais, S.A., de Aquino, F.J.T., Cunha, L., Silva, L.D.O., Martins, C.H., Teixeira, T.L., \& da Silva, C.V. (2020). Chemical Composition and Bioactive Potential of Essential Oils from Banisteriopsis campestris. Current Bioactive Compounds, 16(8), 1205-1214.

Roy D.C., Barma, S.K., \& Shaik, M.M. (2013). Currents Updates on Centella asiatica: Phytochemistry, Pharmacology and Traditional Uses. Medicinal Plant Research, 3(4), 20-36.

Savitri A., Martini, M, \& Yuliawati, S. (2016). Keanekaragaman Jenis Rayap Tanah dan Dampak Serangan pada Bangunan Rumah Di Perumahan Kawasan Mijen Kota Semarang. Jurnal Kesehatan Masyarakat, 4(1), 100-105.

Sieberi, B.M., Omwenga, G.I., Wambua, R.K., Samoei, J.C. \& Ngugi, M.P. (2020). Screening of the Dichloromethane: Methanolic Extract of Centella asiatica for Antibacterial Activities against Salmonella typhi, Escherichia coli, Shigella sonnei, Bacillus subtilis, and Staphylococcus aureus. The Scientific World Journal, 2020, 18.

Zhu, B.C.R., Henderson, G., Yu, Y., \& Laine, R.A. (2003). Toxicity and Repellency of Patchouli Oil and Patchouli Alcohol against Formosan Subterranean Termites Coptotermes formosanus Shiraki (Isoptera: Rhinotermitidae). Journal of Agricultural and Food Chemistry, 51(16), 4585-4588. 